\title{
'n Kritiese analise van die begrip ratifikasie volgens die Gereformeerde Kerkreg
}

\author{
Andries du Plooy \\ Fakulteit Teologie \\ Noordwes-Universiteit Potchefstroomkampus
}

\begin{abstract}
A critical analysis of the concept ratification according to Reformed church polity

This article reflects critically on the view that local churches should in a separate act, after major assemblies have taken their resolutions, ratify the decisions before it could be regarded as valid and binding. Attention is given to the following aspects: The meaning of expressions such as ratum facere and ratum habere in law and church polity; perspectives from the Reformational approach on issues such as the authority of decisions of major assemblies and a critical evaluation of the arguments of protagonists in favour of ecclesiastical ratification.
\end{abstract}

\section{INLEIDING}

Vir die voorreg om in hierdie feesbundel by geleentheid van die eeufees van die Universiteit van Pretoria 'n teologiese bydrae te mag maak, voel ek opreg dankbaar en vereer.

Die Fakulteit Teologie van die Universiteit van Pretoria het nie net 'n besondere plek en funksie aan daardie universiteit nie, maar ook in die geledere van ander teologiese fakulteite in nasionale en internasionale verband. Ook op die terrein van die kerk en samelewing in Suid-Afrika het dit voortdurend 'n duidelike effek en impak.

Namens myself en namens die Fakulteit Teologie van die NoordwesUniversiteit (veral van die Potchefstroomkampus) wens ons $u$ as Universiteit en Fakulteit van harte geluk met $u$ honderdste verjaardag.

In die teologiese tydskrifte wat aan bepaalde instellings/universiteite/ fakulteite verbind word, het teoloë die geleentheid om in die beoefening van die teologie (onvermydelik) vanuit 'n bepaalde tradisie of paradigma, tegelyk 


\section{'n Kritiese analise van die begrip ratifikasie}

meer van mekaar te leer en mekaar beter te verstaan. So vervul die HTS reeds ' $n$ besondere rol in die beoefening van die teologie, en kan die aksente en paradigma van die Hervormde teologie duidelik bemerk word.

Die onderwerp waaroor ek skryf, is nie iets wat binne die tradisie van die Hervormde teologie, en meer in besonder, binne die Hervormde kerkregtelike tradisie prominent is nie. Tog is 'n gesprek oor ratifikasie - al sou dit dalk op die periferie van die Nederduitsch Hervormde Kerk in Afrika se fokus lê - in die breë en algemene gereformeerde/hervormde kerkregtelike geskiedenis ' $n$ interessante en problematiese onderwerp.

Die begrip ratifikasie (ratificatio) het veral in Nederland, gedurende die veertigerjare, in die tyd van die sogenaamde Vrymaking prominent gefigureer. Ratifikasie het te doen met die geldigmaking van besluite. Dit is 'n samevoeging van twee Latynse woorde, ratum en facere wat die betekenis het om iets geldig te maak.

Besinning oor die aangeleentheid geniet feitlik deurgaans die aandag van gereformeerde kerke in Nederland (Bouma 1994:381), en voortdurend word besprekings gevoer oor die ratifisering en "effectueren" van besluite van meerdere vergaderinge (Te Velde 1994:309-310).

In die geledere van die Gereformeerde Kerke in Suid-Afrika het dit vroeër nooit soveel prominensie soos by die kerke in Nederland geniet nie, hoewel daar sedert die negentiger jare van die vorige eeu aanduidings is dat al meer daaroor geskryf en gedebatteer word (Meijer 1995; Visser 1999:141, 334, 339).

Die aktualiteit van die saak het egter baie skerp na vore gekom na die Sinode van die Gereformeerde Kerke in Suid-Afrika in Januarie 2003. In Die Kerkblad (en ook in ander kerklike blaaie soos Dwaling en Waarheid, en Kerkpad wat besonder krities fokus op gebeure in die verband van die Gereformeerde Kerke in Suid-Afrika, maar wat nie onder die sorg van deputate van 'n Nasionale Sinode uitgegee word nie) is dit duidelik dat daar verskillende standpunte en sienings oor die geldigheid van kerklike besluite bestaan. Daar is aanduidings dat daar by sommiges 'n sterk afwysende houding teenoor bepaalde besluite van die Sinodes is, veral ten opsigte van besluite wat geneem is oor die nuwe Psalmomdigting en die toelating van vrouens tot die amp van diaken. In die diskussies en gesprekke hieroor word dikwels verwys na ratifikasie van besluite, en verskillende standpunte word gestel oor die gesag van kerklike besluite, oor die verhouding tussen plaaslike kerke en meerdere vergaderinge en oor aanverwante sake (vgl Cilliers 2003:45-46; Du Plooy 2003:47-50; Momberg 2003:43-45; Kruger 2003:45-46; Van Wyk 2003:7-8). 
In hierdie artikel fokus ek op die volgende aspekte:

- Die uitdrukkings: ratum facere en ratum habere (art 31 DKO) en die betekenis daarvan in die reg en kerkreg;

- Perspektiewe uit die geskiedenis van die Gereformeerde kerke vanaf die Reformasie;

- 'n Kritiese evaluering van die grondslag waarop die ratifikasiereg berus;

- Samevattende opmerkings

\section{RATUM FACERE EN RATUM HABERE EN DIE BETEKENIS DAARVAN IN DIE REG EN KERKREG}

Vanaf 1581 met die Sinode van Middelburg (art 23) kom die woorde ratum habere in die kerkordes van die gereformeerde kerke voor. "Si quis minoris conventus sententia se gravari queretur, ad superiorem erit provocatio. Quod vero plurium suffragiis erit probatum, id ratum habebitur, nisi verbo Dei, aut etiam articulis a Synodo generali constitutis, donec alia synodo generali mutentur, adversari ostendatur" (Rutgers 1889:384).

Indien iemand kla dat die vergadering se besluit hom veronreg, mag daar 'n beroep op 'n meerdere vergadering wees. Wat met die meeste stemme as waar (goed) beskou word sal as vas en bindend gehou word, tensy bewys word dat dit in stryd is met die Woord van God of die artikels wat deur die algemene Sinode vasgestel is, solank as dit deur geen ander algemene Sinode verander is nie.

In 1618/19 met die Sinode van Dordrecht (art 31) is net soos in die Sinode van Middelburg 1581 (art 23) die reg van appèl wat in 1578 (Sinode te Dordecht, art 19) nog afsonderlik gestel was, in een artikel, gekombineer. Dit beteken dat artikel 31 DKO twee sake stel, naamlik die reg tot appèl en die bindende regsgeldige krag van besluite.

In hierdie verband kom die woorde ratum habere telkens voor, terwyl die woorde ratum facere nie in die Gereformeerde kerkordes van die $16 \mathrm{e}$ en 17 e eeue voorkom nie.

Meijer (1995:6-14) het grondig ingegaan op die voorkoms en betekenis van die woorde ratum habere in die reg en in die kerkreg. Dit is duidelik dat die Sinode van Dordrecht 1578 (hfst 2, art 8) bepaal het dat besluite wat met die meeste stemme geneem is, deur almal nagekom moet word "het welcke 


\section{'n Kritiese analise van die begrip ratifikasie}

besluyt een yeghelick schuldich sal syn na te komen" (Rutgers 1889:241). In 1581 is hierdie bewoording in artikel 23 verander en vervang met ratum habebitur: "sal voor vast ende bondich ghehouden werden" (Rutgers 1889:384).

Wanneer enkele regsbronne nagegaan word (Van Jaarsveld 1971; Hiemstra \& Gonin s a 275) blyk dit dat opsommend die volgende gevolgtrekkings gemaak kan word:

- $\quad$ Daar is geen noemenswaardige verskil tussen ratum facere en ratum habere in die Romeinse reg nie (Van Jaarsveld 1971:2, 14);

- $\quad$ Albei terme dui op die verlening van terugwerkende regskrag;

- $\quad$ Dit dui op die bevestiging en bekragtiging van dit wat 'n verteenwoordiger elders namens iemand besluit het.

Meijer (1995:9) skryf soos volg:

In die Hollandse reg van die sewentiende en agtiende eeu kom die begrip "mandaat" saam met ratihabitio na vore (Van Jaarsveld 1971:124). 'n Gestor ontvang volmag (mandaat) van die dominus om namens hom sekere regshandelinge te verrig. Wanneer die gestor in ooreenstemming met sy mandaat opgetree het, word dit deur die dominus bekragtig (ratihabitio). Sodoende verleen die dominus regsgeldigheid aan die handelinge van die gestor.

Gedurende die vroeë tyd van die reformasie (veral die tydperk waarop die kerke begin het om saam te kom in vergaderinge (bv te Wesel in 1568 en te Emden in 1571) was die kerke versigtig om nie weer soos in die Rooms Katolieke Kerk 'n kerklike heerskappyvoering of dominokrasie met konsilies en Sinodes te skep nie. Derhalwe is herhaaldelik verklaar dat die Woord van God die enigste gesag in die kerk is, en dat besluite wat daarmee in stryd is, nie aanvaarbaar is nie (vgl NGB art 27-32).

Rutgers (1971:24) toon aan dat dit in daardie vroeë tye van die reformasie die gewoonte was dat kerkordes, nadat dit op meerdere vergaderinge vasgestel is, ook op die agenda van mindere vergaderinge behandel is, en daar ook aangeneem is. Dit is volgens Rutgers skynbaar oorbodig en uitsonderlik, en tog was dit as 't ware geratifiseer deur die mindere vergaderinge. Rutgers toon egter verder aan dat die gewoonte mettertyd verander het, en dat die geldigheid van besluite geheel en al op die onderlinge instemming deur die kerke in meerdere vergaderinge berus het. Die gewoonte het ontstaan dat alle veranderinge aan besluite van die 
kerkorde tydens die Sinodes deur al die afgevaardigdes onderteken is, daarmee afgehandel is en as bindend beskou is (Rutgers 1971:27-41).

\section{PERSPEKTIEWE UIT DIE GESKIEDENIS VAN DIE GEREFORMEERDE KERKE SEDERT DIE REFORMASIE}

Dit is in die Reformatoriese tradisie bekend dat Calvyn dit beklemtoon dat Christus alleen oor alle mag en gesag in die kerk en in die wêreld beskik. In sy Institusie kom dit dikwels aan die orde, veral in boek 4 (vgl 4, 8, 2 en 10; 4, 9, 8 en 9). Calvyn laat blyk dat hy die gesag van konsilies erken, mits die besluite op die Woord van God berus en onder leiding van Christus as die eintlike Voorsitter geneem is.

Hierdie standpunte van Calvyn het bygedra tot die geloofsbelydenisse van die Reformatoriese kerke waarin dit onder meer bely word dat Christus die enigste Hoof en Koning is (NGB art 27-32).

Met die invoering van 'n bekende regsterm naamlik ratum habere in 1581 , soos hierbo aangetoon is, het die kerke van die reformasie duidelik getoon dat hulle die besluite wat in ooreenstemming met die Woord van God en onder leiding van die Heilige Gees geneem het, van groot belang ag. Soveel so dat die kerke wat die vergadering saamstel, hulle daaraan moet verbind om die besluite uit te voer. Dit dien as voorsorg daarteen dat kerke op independentistiese manier geen erns sal maak met besluite van meerdere vergaderinge nie.

Meijer $(1995: 2,118)$ verskil hiervan, en hy stem eerder saam met Deddens se standpunt dat die ratifisering (sinoniem vir ratihabitio) van besluite van meerdere vergaderinge ' $n$ tweede daad van die afsonderlike kerke is, en wat volg op die besluit-daad van die meerdere vergadering. Die regsgeldigheid word eers verleen wanneer die kerke dit hul eie gemaak het by wyse van 'n afsonderlike besluit daaroor, dit wil sê na toetsing daarvan. Eers daarna behoort dit deur die kerke uitgevoer te word (vgl Meijer 1995:47).

As bewys vir hierdie standpunt beweer hy dat dit juis in die reformasie die praktyk was: "Geen besluit van 'n meerdere vergadering is in die plaaslike kerke toegepas alvorens die kerkrade dit nie behoorlik getoets, geldig verklaar en aangeneem het nie" (Meijer 1995:82; vgl ook 83-89). Die vraag is of so 'n stellige bewering in alle opsigte waar is.

Wanneer die geloofsbriewe wat gedurende die $16 \mathrm{e}$ eeu gebruik was, nagegaan word, is dit duidelik dat die standpunte van Deddens (s j: 50-51) en van Ketel (1948:113-114), asook van Meijer (1995:82-89), naamlik dat kerke telkens eers opnuut alle besluite getoets het alvorens die kerke dit uitgevoer het, met 'n beroep op die praktyk in die $16 \mathrm{e}$ eeu, nie korrek is nie. Dit is waar dat kerke en mindere vergaderinge soms kritiek op besluite van Sinodes 


\section{'n Kritiese analise van die begrip ratifikasie}

gehad het, en van die besluite nie uitgevoer het nie, maar die kredensiebriewe laat blyk dat die lasgewers of kerke hulle verbind het om die besluite na te kom en in werking te stel.

Die kredensiebrief van klassis Edam laat blyk dat die kerke wat deputeer volmag en gesag gee aan hul afgevaardigdes asof hulle self in persoon daar teenwoordig is. Verder verbind hulle hulle daaraan dat hulle afgevaardigdes reeds die besluite van die meerdere vergadering approbeer en ratifiseer (Rutgers 1889:293-294). So-ook in die kredensiebrief van klassis Enkhuysen is dit duidelik dat die lasgewers hulle daaraan verbind om wat daar volgens Gods Woord besluit is, self te hou en ook na te kom en in werking te stel (Rutgers 1889:292). In die kredensiebrief van klassis Delft en Rotterdam belowe en onderneem die klassis wat die broeders stuur/afvaardig onder meer die volgende: hulle moet op die Sinode namens die kerke handel, beraadslaag en besluit. Dit wat besluit is, sal deur hulle geag word gedoen gewees het asof hulleself daar teenwoordig was "ende helpen besluyten hadden" (Rutgers 1889:297).

In hierdie dokumente is nêrens 'n verwysing na die voorlopige aard van besluite nie, asof die meerdere vergadering eintlik adviese aan die kerke gee nie.

In die geskiedenis van die Gereformeerde kerke in Nederland gedurende die $19 \mathrm{e}$ en $20 \mathrm{e}$ eeue, was daar baie woelinge en spanninge wat onder meer tot die Afskeiding in 1834, die Doleansie in 1886, en die Vrymaking in 1944 gelei het. Die stryd het telkens in 'n groot mate oor die verhouding tussen plaaslike kerke en meerdere vergaderinge en insgelyks oor die gesag van Sinodes en die bindende krag van besluite van meerdere vergaderinge gegaan (Du Plooy 1979:110 e v; Meijer 1995:97-127).

Teen hierdie agtergrond van spanning en verwarring het $P$ Deddens (1946) sy intreerede in 1946 gehou met as titel: De ratificeering der besluiten van meerdere vergaderingen.

Dit is duidelik dat die reaksie van teoloë en kerke in die tyd van die Vrymaking hewig en skerp was. Dit is ook te verstaan aangesien die sinodale struktuur van die Gereformeerde Kerken in Nederland asook die opkoms van die sogenaamde nuwe kerkreg onder leiding van $\mathrm{H} \mathrm{H}$ Kuyper, J Jansen, M Bouwman en andere sinodalisties was en verskil van die vorige standpunte. Veenhof (1949:20) meen dat die sogenaamde nuwe kerkreg die wesenlike aspekte van die gereformeerde kerkreg aangetas het, deurdat die Sinodes hulleself meer mag en gesag toe-eien en heerskappy oor die kerke voer. Dit het veral in die tydperk van 1926 met die Geelkerken-saak tot die Vrymaking in die veertigerjare ontwikkel, en in 'n sekere sin voltooiing gevind in die nuwe kerkorde van die Gereformeerde Kerken in Nederland wat in 1959 aanvaar is (Nauta 1971:35). 
In 'n publikasie van Schilder en Deddens(s $\mathrm{j})$ is die titel veelseggend: Eerste- en tweedehands gezag. Hierin word betoog dat ' $n$ Sinode se gesag ontleen en afgelei is; derhalwe is dit beperk, en tweedehands in vergelyking met die gesag van 'n kerkraad wat eerstehands gesag het (bl 12-13).

In die geledere van die Vrygemaakte kerke in Nederland (Gereformeerde kerken Nederland, vrijgemaakt) is daar egter nie eenstemmigheid met die menings van Deddens en Schilder nie. Kamphuis (1970:55-71) spreek hom uit teen die standpunt dat daar 'n tweede bewuste daad van 'n kerkraad moet kom om besluite van meerdere vergaderinge geldig te maak of geldig te verklaar. Hy meen dat dit sodoende die besluite van Sinodes tot adviese sou degradeer (bl 64). Hy het bewustelik teen die sogenaamde ratifikasie-reg gekies (Meijer 1995:134).

In 1994 het Te Velde (309-310), hoogleraar in kerkreg te Kampen die volgende verklaar: "... een synodebesluit wordt principieel gezien niet pas van kracht doordat een speciale toegevoegde actie van de kerkeraad plaatsvindt. Zo 'n besluit heeft niet de bekrachtiging van een kerkeraad nodig om bindend te worden". Hy beklemtoon verder dat kerke besluite moet toets aan die Woord, maar nie so asof dit dan eers geldig verklaar word nie, omdat die besluite reeds wettig en bindend is.

Die geloofsbrief wat in die Gereformeerde kerken Nederland (Vrijgemaakt) gebruik word, laat blyk dat die kerke "overeenkomstig artikel 31 van de kerkorde de uitspraken die bij meerderheid van stemmen zijn gedaan als bindend zal aanvaarden, tensij wordt bewezen dat zij in strijd zijn met het Woord van God of met de kerkorde ..."; en dan vind ons die volgende bewoording in die geloofsbrief: "Hij gaf deze broeders last en volmacht om namens hem en als was hij zelf in zijn geheel in de classis tegenwoordig volgens het Woord van God en in gebondenheid aan de drie formulieren van eenheid ..." deel te neem (Bouma 1983, bylaag 24-1).

Die geloofsbrief wat in terme van artikel 33 van die kerkorde van die Gereformeerde Kerke in Suid-Afrika gebruik word, lui soos volg:

Hierdie broeders ontvang hiermee las en volmag om namens die kerkraad volgens die Woord van God, die Formuliere van Eenheid en die aanvaarde kerkorde in alle sake wat op die klassis sal voorkom te help oordeel en besluit tot bloei van die kerke, tot uitbreiding van God se koninkryk en tot verheerliking van die Naam van die Here. Die kerkraad verbind hom om alle besluite van die klassis wat nie met genoemde reël in stryd is nie, as vas en bindend te beskou en dit getrou te help uitvoer en nalewe.

(Acta 1985:560) 


\section{'n Kritiese analise van die begrip ratifikasie}

Volgens artikels 30 en 46 van die kerkorde van die Gereformeerde Kerke in Suid-Afrika (in ooreenstemming met die DKO) is daar sprake van dat besluite in meerdere vergaderinge afgehandel moet word. Met ander woorde: wanneer besluite deur meerdere vergaderinge geneem is, is dit afgehandel. Alle besluite moet binne die raamwerk van die Skrif, belydenis en kerkorde geneem word, en om daardie rede moet dit as vas en bindend gehou word. Dit is 'n onderneming wat gegee word, en waaraan kerke wat afvaardig hulle aan verbind het. Daar is natuurlik die voorbehoud dat wat in die opdrag of mandaat aan die afgevaardigdes na meerdere vergaderinge gestel word, moet gebeur. Dit is dat besluite binne die gestelde raamwerk geneem moet word. Indien dit bewys word dat dit nie so is nie, is die besluite natuurlik nie geldig nie.

Voetius het in sy definisie van meerdere vergaderinge gestel dat dit 'n wettig byeengeroepte vergadering is, bestaande uit afgevaardigdes van meer kerke om kerklike sake en aangeleenthede te behandel en af te handel. "Conventus legitime convocati, constantes ex delegatis plurium ecclesiarum ad negotia et causas ecclesiasticas tranctandas atque absolvendas" (O'Brien Geldenhuys 1951:250). Hieruit is dit duidelik dat meerdere vergaderinge sake afhandel, en dat daar nie eers gewag word vir plaaslike kerke om alles weer te behandel en te ratifiseer nie, asof daar 'n dualisme tussen die plaaslike kerk en die meerdere vergadering is.

\section{KRITIESE EVALUERING VAN DIE GRONDSLAG WAAROP DIE "RATIFIKASIEREG" BERUS}

In 'n vorige studie het ek aangedui wat die verskillende standpunte oor die wese van meerdere vergaderinge is (Du Plooy 1979:113-115). Die konklusie was dat ' $n$ meerdere vergadering ' $n$ vergadering van kerke is waarheen afgevaardigdes in die lerende en regerende ampte gestuur word, aangesien die werk van regering aldaar in terme van veral artikel $30 \mathrm{KO}$ in belang van mekaar en van ander kerke verrig word.

Die standpunt van Meijer (1995:61) dat meerdere vergaderinge hulle nie met die regering van kerke besig hou nie, of daarmee mag besig hou nie, vind geen steun in 'n Skriftuurlike ampsbegrip nie (vgl bv Efesiërs 4 en 1 Korintiërs 12:28 e v en bespreking daarvan in Du Plooy 1982:201-202 en Ridderbos 1954:96-97).

Indien die standpunt dat meerdere vergaderinge hulle nie met die regering van kerke besig mag hou nie, een van die redes is vir die ratifisering van die besluite van meerdere vergaderinge omdat alleen plaaslike kerke met die regering van die kerke besig is, is dit duidelik 'n ongeldige standpunt. Die vernaamste rede vir die ongeldigheid van sodanige standpunt is die volgende: 
'n meerdere vergadering is juis 'n vergadering van meer plaaslike kerke wat deur hulle afgevaardigdes by wyse van kredensiebriewe gebind is om bindende besluite te neem binne die raamwerk van die Skrif, die belydenis en die kerkorde. Dus, plaaslike kerke is daar teenwoordig. Slegs as daar 'n dualistiese spanning bestaan tussen 'n plaaslike kerk en 'n meerdere vergadering, kan daar geredeneer word oor die vraag wie nou eintlik die meeste gesag het. Ons het reeds aangetoon dat dit in wese 'n valse probleemstelling is omdat alle kerklike ampte en vergaderinge geroep is om slegs die gesag van Christus as die enigste Hoof van die kerk in en aan die kerke te bedien.

Die vraag na die gesag van meerdere vergaderinge word ook verskillend beantwoord. En dit lyk of sommige voorstaanders van die ratifisering van besluite by wyse van 'n tweede daad van die kant van kerkrade, van die veronderstelling uitgaan dat 'n meerdere vergadering afgeleide gesag het, of tweedehandse gesag het (Schilder \& Deddens, s a: 17), en daarom is kerkrade wat eerstehandse gesag het, verplig om die besluite te toets en geldig te maak.

Daar bestaan die gedagte of standpunt dat die gesag van meerdere vergaderinge afgeleide gesag is. Sommiges lei dit af van die amp, ander lei dit af van die kerke wat afgevaardigdes stuur. Wie dit aflei van die kerke wat stuur, meen dat die eintlike gesag dus by die plaaslike kerke berus, en diegene soos M Bouwman wat dit aflei van die ampte wat byeen is in die meerdere vergaderinge, meen dat dit kumulatief meer gesag byeen bring sodat die gesag van meerdere vergaderinge dus weer groter is as die van die plaaslike kerke (vgl Du Plooy 1979:121).

Ek meen dat die suiwer Gereformeerde standpunt is dat Christus alleen gesag het in die kerk, en dat die kerke in al sy handelinge, ook in alle vergaderinge geroep is en daartoe verbind is om alleen maar hierdie gesag van Christus te bedien in belang van die kerke wat in die vergaderinge verteenwoordig word (Du Plooy 1979:123-128).

Toegepas op die vraag of dit nodig en noodsaaklik is dat 'n plaaslike kerk na ' $n$ meerdere vergadering deur ' $n$ afsonderlike daad moet vasstel of toets of die besluite gesagvol en derhalwe geldig is - asof die kerkraad oor die eintlike bevoegdheid daaroor beskik - hou nie rekening met die feit dat alle vergaderinge geroep is om die gesag van Christus te bedien nie. Deddens (1946:13) hou myns insiens nie genoegsaam rekening met hierdie feit nie, aangesien dit sy standpunt is dat 'n afgevaardigde se werk deur sy lasgewer getoets moet word alvorens dit bindend kan wees. Hierteenoor moet gestel word dat die kerke na 'n meerdere vergadering nie meer met die afgevaardigdes te doen het nie, maar met besluite van meer kerke wat 


\section{'n Kritiese analise van die begrip ratifikasie}

wettiglik byeen was om die gesag van Christus te bedien. Die gesag van Christus word bedien deurdat en wanneer ' $n$ kerklike vergadering onder leiding van die Heilige Gees die lig of getuienis van die Woord van God oor 'n bepaalde saak verstaan en besluite in die lig daarvan neem. In hierdie verband is die gebeure wat in Handelinge 15 beskryf word, rigtinggewend. Nog duideliker is die aanduiding in Handelinge 16:4 waaraan later meer aandag gegee sal word.

Die besluite is om daardie rede geldig en bindend. Geldigheid beteken egter nie onfeilbaarheid nie. Dit is moontlik dat besluite in stryd met die Woord van God geneem is.

Die afspraak van die kerke in terme van artikels 31 en 86 DKO is egter dat daardie kerke wat meen dat 'n besluit wat nie met die Woord van God en/of die kerkorde ooreenstem nie, dit moet bewys. Die bewyslas rus op diegene wat glo dat die besluite verkeerd is.

Op die vraag of kerke verplig is om besluite as bindend en geldig te hou en tot uitvoer te bring terwyl hulle in hul gewete oortuig is dat dit stry met die Woord van God, moet beslis geantwoord word dat dit geensins vereis mag word nie. 'n Interessante uitspraak hieroor is in 1945 deur die Amsterdamse Hof geneem. Dit lui soos volg:

dat in het licht van dit beginsel (t.w. art 84 DKO) aan de beperking van de geldigheid der besluiten van meerderen vergaderingen, in art. 31 einde vervat, geen andere betekenis kan worden gehecht, dan dat deze besluiten niet gelden t.a.v. die kerken die van oordeel zijn, dat bewezen is, dat zij streden met het Woord Gods.

Verder het die Hof aandag gegee aan sitate uit Voetius se Politica Ecclesiastica, en volg dan met die verdere gevolgtrekking:

dat in het oude Gereformeerde Kerkrecht steeds gehoorzaamheid aan Gods Woord en het geweten is gesteld boven gehoorsaamheid aan besluiten van synoden enz. En voorts dat onder bepaalde omstandigheden als uiterste middel de losmaking van het kerkverband mogelijk is, ja, zelfs geboden kan zijn.

(Hardenberg s a:1000; ook Roeleveld 1964:168-169; Roeleveld 1958:52-61)

Plaaslike kerke het dus die reg om besluite van meerdere vergadering in gevalle waar die oortuiging bestaan dat gewetens nie gebind mag word aan besluite wat met die Woord van God in stryd is nie, nie te aanvaar nie, maar vanweë die onderlinge afspraak (art $86 \mathrm{KO}$ ) en die eis van artikel 31 moet dit 
aan die kerke in kerkverband bewys word op ordelike wyse (vgl Roeleveld, 1958:53).

'n Belangrike aspek is natuurlik die vraag of die Woord van God lig werp op die vraag na die bindende karakter en geldigheid van besluite van meerdere vergaderinge.

In die Skrif vind ons geen meerdere vergadering soos ons dit in die gereformeerde kerkreg ken nie, maar dit is wel duidelik uit die Skrif dat meerdere vergaderinge nie met die Skrif in stryd is nie, en noodwendig volg en noodsaaklik is vir die opbou van die kerke (Du Plooy 1979:102 e v; 1982:227 e v).

In die Gereformeerde tradisie is daar eenstemmigheid dat ons in Handelinge 15 belangrike beginsels vind vir die wyse waarvolgens kerke mekaar moet bystaan in meerdere vergaderinge (Calvyn 1966:31; Bouwman 1937; Du Plooy 1982:236-238).

In Handelinge 16:4 word dit duidelik dat die verordeninge wat vasgestel is tydens die vergadering in Jerusalem aan al die kerke wat Paulus en sy reisgenote verder besoek het, gegee is om te onderhou. In Grieks staan dit sterk uitgedruk: ta dogmata ta kekrimena (leerstellings waarop besluit is/wat vasgestel is), paredidosan autois phulassein (is aan hulle oorgegee om te onderhou).

Die werkwoord om te onderhou (phulassein) is 'n werkwoord wat ook gebruik word wanneer gestel word dat die woord van God onderhou moet word (Luk 11:28; Matt 19:20).

Dit beteken dat die kerke aan die besluite van die vergadering in Jerusalem gehoorsaam moes wees omdat die besluite in die lig van die Woord en onder leiding van die Heilige Gees geneem is.

Ter wille van duidelikheid moet gestel word dat besluite van meerdere vergaderinge inderdaad ook feilbaar is en in stryd met die Woord kan wees.

Die kerke is afsonderlik en ook gesamentlik verantwoordelik om sorg te dra dat dit reggestel moet word. In hierdie verband is Handelinge 15 'n goeie aanduiding van hoe kerke en ouderlinge en apostels mekaar bygestaan het wanneer 'n probleem hanteer moet word. Benewens Handelinge 15 vind ons die beginsel in die Skrif - 1 Korintiërs 14:29 - dat die uitsprake of standpunte van twee of drie profete deur ander beoordeel moet word - 'n teks waarop Calvyn die reg en sin van meerdere vergaderinge baseer. Die wyse Spreuke (11:14) sê: "In die veelheid van raadgewers is redding". (Vgl ook Spreuke 24:6.)

Vanuit die feit dat God genadegawes en dienste aan en in sy kerk (1 Kor 12:28) gegee het, volg dit vanself dat kerke hulle gawes en dienste tot welsyn en opbou van al die kerke moet aanwend (Ef 4:11-16). So behoort die 


\section{'n Kritiese analise van die begrip ratifikasie}

kerke mekaar by te staan, en sorg te dra dat volhoudend vasgestel word of die besluite die gesag van Christus in en aan die kerke bedien (vgl Du Plooy 2005:555-567).

Die insig en verstaan van die wil van God bly al die kerke se verantwoordelikheid, en sodoende is daar dan inderdaad 'n beter manier om die wil van God vas te stel as wanneer enkele kerke met minder gawes en insigte dit op hul eie wil doen. In die gebed van Paulus vir die Efesiërs (Ef 3:18) laat blyk hy dat die kerk "saam met al die heiliges" moet nadink oor die liefde van God in en deur Jesus Christus. 'n Plaaslike kerk staan nooit in spanning teenoor of in onafhanklikheid van die ander plaaslike kerke van Christus nie. Daar is maar een kerk van God wat op baie plekke tot openbaring of vergestalting kom (vgl ook 1 Kor 1:1-2).

\section{SLOTOPMERKINGS}

Die standpunt van Deddens en van Meijer waarna verwys is, naamlik dat daar na afloop van 'n meerdere vergadering 'n tweede daad van besluitneming deur elke plaaslike kerk moet wees, gaan in die lig van bogenoemde gegewens nie op nie.

Die mening van Boersma (1994:51) dat Sinodebesluite wel nie deur die kerke goedgekeur moet word nie, maar tog geratifiseer moet word, dit wil sê regskrag verleen word of bekragtig moet word, beteken in essensie eintlik dieselfde as 'n tweede beslissing oor afgehandelde sake.

Die voorstel van Meijer (1995:183 e v) dat 'n bepaalde prosedure moet volg by kerkrade na 'n meerdere vergadering, berus hoofsaaklik op die standpunte van Deddens en Boersma. Sy voorstel is dat soos volg te werk gegaan word:

- $\quad$ Toetsing van alle besluite by wyse van bestudering van die besluite;

- Verklaring van geldigheid of ongeldigheid na gelang die uitslag van die studie;

- Indien dit geldig verklaar word, moet die kerkraad die besluite as hul eie aanvaar;

- Indien dit ongeldig verklaar is, onderneem die kerkraad om die bewyse daarvoor aan die kerke bekend te maak;

- $\quad$ Laastens die uitvoering van besluite wat geldig verklaar is.

Ek meen dat aangetoon is dat hierdie wyse van ratifikasie van besluite van meerdere vergaderinge, nie steun vind in die Skrif nie, nie in die Dordtse kerkorde nie, en ook nie in die geskiedenis van die reformasie nie. 
In stede daarvan behoort aanvaar te word dat die afgevaardigdes na meerdere vergaderinge binne hul mandaat en binne die raamwerk van die Skrif, belydenis en kerkorde (soos duidelike geformuleer in die geloofsbriewe [art 33 kerkorde], in terme waarvan meerdere vergaderinge gekonstitueer word) aan die proses van bespreking van sake en besluitneming deelneem.

Kerke het hulle by voorbaat daaraan verbind om die besluite te gehoorsaam en toe te pas omdat dit binne die raamwerk van die Skrif, die belydenis en die kerkorde, soos in die geloofsbriewe geformuleer, geneem is. Tussen die plaaslike kerk en die meerdere vergadering bestaan daar geen dualistiese verhouding nie, omdat 'n meerdere vergadering ' $n$ vergadering van kerke is, waar besluite geneem word asof die kerke self daar teenwoordig is (vgl Rutgers 1889:297).

Kerke behoort egter op 'n effektiewe wyse ingelig te word oor die besluite wat op 'n meerdere vergadering geneem is - nie om dit geldig te maak nie, maar om dit uit te voer en te gehoorsaam, en om - indien hulle meen dit in stryd is met die Woord van God, die kerklike weg van beswaar of appèl te volg.

\section{Literatuurverwysings}

Boersma, A 1994. Met de besluiten aan het werk. Reformanda 4(5), 49-51.

Bouma, H 1983. Kerkorde van de Gereformeerde Kerken in Nederland. Groningen: De Vuurbaak.

Bouma, H 1994. De diakenen en de "ratificatie" van synodebesluiten. Reformanda 4(28), 381-382.

Bouwman, M 1937. Voetius over het gezag der synoden. Academisch proefschrift ter verkrijging van den graad van doctor in de heilige Godgeleerdheid.

Amsterdam: Bakker.

Calvyn, J 1559. Institusie van die Christelike Godsdiens, Deel 4, vertaal deur H W Simpson. Potchefstroom: CJB.

Calvyn, J 1966. The acts of the apostles, in Torrance, D W \& Torrance, T F (eds), tr by J F Fraser, Calvin's Commentaries, vol 1. Edinburgh: Oliver \& Boyd.

Cilliers, $S$ 2003. Gereformeerde kerk Waterberg (Dolerend) - waarheen? Kerkblad 106(3150), 45-46.

Deddens, P s a. Is het een vreemde en ongereformeerde praktijk, dat de synodebesluiten door de mindere vergaderingen worden goedgekeurd?, in Schilder, K \& Deddens, P s a, Eerste- en tweedehand gezag: Bijdrage tot de kennis der jongste kerklijke procedure. Groningen: De Jager.

Deddens, P 1946. De ratificeering der besluiten van meerdere vergaderingen. Rede uitgesproken bij de aanvaarding van het Hoogleraarsambt aan de Theologiesche Hoogenschool te Kampen op Maandag 28 Januari 1946.

Du Plooy, A le R 1979. Ekklésia en meerdere vergaderinge. ThM-verhandeling, Potchefstroomse Universiteit vir $\mathrm{CHO}$. 
Du Plooy, A le R. 1982. Kerkverband: 'n Gereformeerd-kerkregtelike studie. ThDproefskrif, Potchefstroomse Universiteit vir $\mathrm{CHO}$.

Du Plooy, A le R 2003. Doleansie en ratifikasie - reaksie op besluite van Waterberg. Kerkblad 106(3150), 47.

Du Plooy, A le R 2005. Die betekenis van charisma en amp vir die kerkregering. In die Skriflig 39(3), 555-567.

Geldenhuys, F E O'Brien 1951. Die regsposisie van kerkraad, ring en Sinode onder die gereformeerde stelsel van kerkregering soos toegepas in die Gefedereerde Ned Ger Kerke in Suid-Afrika. Pretoria: Van Schaik. (Proefskrif - D.L.)

Gereformeerde kerke in Suid-Afrika 1985. Handelinge van die twee en veertigste Nasionale Sinode in Potchefstroom. Potchefstroom: Herald.

Hiemstra, V G \& Gonin, H L s a. Drietalige Regswoordeboek.

Kamphuis, J 1970. Kerkregtelijke besluitvaardigheid. Rede gehouden bij de overdracht van het rectoraat der Theologische Hogenschool van de Gereformeerde Kerken in Nederland op 10 December 1969, 87. Groningen: De Vuurbraak.

Ketel, C J 1948. Hoe men handelende in het begin der reformatie in Nederland ten aanzien van art. 31 K.O. De Reformatie 23(14), 113-114.

Kruger, H 2003. Moet kerke besin of Sinode reg met Skrif was. Kerkblad, 105(3149), 25-26.

Kruger, H 2003. Beproef die geeste - nogeens. Kerkblad 106(3151), 45-46.

Meijer, G J 1995. Ratifikasie in die gereformeerde kerkreg. ThM-verhandeling, Potchefstroomse Universiteit vir $\mathrm{CHO}$.

Momberg, H L J 2003. Stel die geeste op die proef. Kerkblad 106(3150), 43-45.

Nauta, D 1971. Verklaring van de Kerkorde van de Gereformeerde Kerken in Nederland. Kampen: Kok.

Ridderbos, H N 1954. The Epistle of Paul to the churches of Galatia. London: Marshall, Morgan \& Scott.

Roeleveld, L 1958. Gereformeerde Kerken in het privaatrecht. Zeist: Steenbergen.

Roeleveld, L 1964. De Vrijmaking als legitimasie van de Gereformeerde Kerken in Nederland. Dienst 13(10-12), 153-197.

Rutgers, F L 1889. Acta van de Nederlandsche Synoden der zestiende eeuw. S'Gravenhage: Nijhoff.

Rutgers, F L 1971. De geldigheid van de oude kerkenordening der Nederlandsche gereformeerde kerken. Met aantekeningen en aktenstukken. Amsterdam: Ton Bolland.

Schilder, K \& Deddens, P s a. Eerste- en tweedehand gezag: Bijdrae tot de kennis der jongste kerkelijke procedure. Groningen: De Jager

Te Velde, M 1994. Uitvoering van synodenbesluiten. De Reformatie 69(15), 309-310.

Van Jaarsveld, S R 1971. Die leerstuk van ratifikasie in die Suid-Afrikaanse verteenwoordigingsreg. Proefskrif, Universiteit van Pretoria.

Van Wyk, J H 2003. Doleansie en toleransie. Kerkblad 106(3151), 7.

Veenhof, C 1949. Om de "Unica Catholica": een beschouwing over de positie van de bezwaarden onder en over de synodocratie. Goes: Oosterbaan \& Le Cointre.

Visser, J 1999. Die kerkorde in praktyk. Roodepoort: J Visser. 